\title{
Response to letter to the editor concerning: Nasir AA, Abdur-Rahman LO, Adeniran JO. Predictor of mortality in children with typhoid intestinal perforation in a tertiary hospital in Nigeria. Pediatric Surg Int 2011; 27:1317-1321. Epub 2011, May 19
}

\author{
Abdulrasheed A. Nasir \\ Accepted: 18 April 2012/Published online: 5 May 2012 \\ (C) Springer-Verlag 2012
}

\section{Dear Sir,}

Re: Letter to the editor concerning: Nasir AA, AbdurRahman LO, Adeniran JO. Predictor of mortality in children with typhoid intestinal perforation in a tertiary hospital in Nigeria. Pediatric Surg Int 2011;27: 1317-1321.

We have read the above letter and wish to thank the author for the valuable information on the possible contribution of host factors like the genes of major histocompatibility complex (MHC) and human leukocyte antigen (HLA) to the occurrence of high proportion of typhoid intestinal perforation in Nigeria. However, facility for genetic association study is lacking in our setting.

The possibility of the presence of abnormal flagellar antigenic components responsible for the intestinal perforation in Nigeria cannot be overruled. We have previously reported the increase in number of multiple perforations involving small and large bowel in our center $[1,2]$. We thus speculated the possible influence of special strain of salmonella organism in our patients. Unfortunately, we cannot phage type these organisms in our center. We however do not think that the Salmonella typhi strain carrying the flagellar antigen variant $\mathrm{H} 1-\mathrm{j}$ is responsible in our patients because the H1-j strain of $S$. enterica serotype typhi has been found to infect older patient and had a milder clinical illness [3] not intestinal perforation, which is a severe form of the disease.

Yours faithfully, Abdulrasheed A. Nasir.

\section{References}

1. Adeniran JO, Taiwo JO, Abdur-Rahman LO (2005) Salmonella intestinal perforation: (27 perforations in 1 patient, 14 perforations in another) Are the goal posts changing? J Indian Assoc Pediatric Surg 10:248-251

2. Nasir AA, Adeniran JO, Abdur-Rahman LO, Odi TO, Omotayo JA (2008) Intestinal disease: 32 perforations in 1 patient. Niger Postgrad Med J 15:55-57

3. Lau SK, Woo PC, Chan CY, Woo WL, Woo GK, Yuen KY (2005) Typhoid fever associated with acute appendicitis caused by an H1j strain of Salmonella enterica serotype Typhi. J Clin Microbiol 43:1470-1472

\footnotetext{
A. A. Nasir ( ()

Division of Paediatric Surgery, Department of Surgery,

University of Ilorin Teaching Hospital, Ilorin, Nigeria

e-mail: draanasir@yahoo.com
} 